\title{
Apuntes a Notas al pie de Gaza. El cómic periodístico de Joe Sacco
}

\author{
Diego Espiña Barros
}

Universidade de Santiago de Compostela

Diego Espiña Barros (Forcarei, 1979) es licenciado en Filología Hispánica por la Universidade de Santiago de Compostela y en Periodismo por la Universidad Carlos III de Madrid. Ha trabajado como periodista para diversos periódicos antes de volver al ámbito académico donde realiza una tesis doctoral sobre memoria y periodismo en cómic. Colabora habitualmente en publicaciones como Jot Down y Luzes. 


\title{
Resumen
}

Tras décadas de disputas sobre la validez del cómic más allá de simple divertimento juvenil, hoy asumimos que no solo es capaz de tratar temas considerados serios sino que asistimos a la eclosión de un género nuevo que algunos llaman "noticias dibujadas". E1 objetivo de este artículo es demostrar en qué medida el cómic es un medio adecuado para llevar a cabo trabajos plenamente periodísticos. Partimos de la base de la candente discusión entre escritura de ficción y escritura de no ficción (¿̨realidad?) y su manifestación en el mundo del periodismo de la mano del llamado Nuevo Periodismo en los años sesenta en EE. UU. Desde esta perspectiva consideramos que las obras de Joe Sacco, especialmente Notas al pie de Gaza (2010), beben directamente de los postulados del Nuevo Periodismo por lo que deben leídas como verdaderos reportajes en un baile de géneros que va desde la pura documentación informativa a la propia lectura literaria.

\begin{abstract}
After decades of disputing the validity of the comic beyond being simple entertainment for young people, today we assume that comic can not only portray topics considered to be serious, but we are seeing the emergence of a new genre that some call "graphic news". The objective of this article is to demonstrate how the comic is an adequate media for journalism. Starting with the base of the hot-topic of writing fiction and writing nonfiction (reality?) and its manifestation in New Journalism in the 1960's in the United States. From this perspective, we will see how the work of Joe Sacco, specifically Footnotes from Gaza (2010), is directly influenced by this debate and should be read as a true journalistic reports that dances between genres offering pure documentation of facts and literary interpretation.
\end{abstract}


Desde sus orígenes, Literatura y Periodismo se han alimentado mutuamente hasta el punto de tener caminos entrelazados a lo largo de la historia. No en vano, buena parte del desarrollo de la novela tiene cabida en las páginas de la prensa; no pocos novelistas han ejercido también de periodistas y viceversa. La narrativa, género fundamental, mantiene vínculos con el discurso periodístico en el sentido en que ambos tienen una naturaleza reproductiva acerca del mundo y cierta relación con lo que llamamos realidad. Fue Daniel Defoe, novelista excepcional y periodista influyente, quien en 1722 publicaría "el primer reportaje novelado conocido", Diario del año de la peste, una minuciosa reconstrucción de la epidemia de peste bubónica que asoló la ciudad de Londres en $1665 .{ }^{1}$ Las raíces de la cultura periodística contemporánea tienen múltiples y variados ahíncos. Para comenzar, en los propios géneros literarios - novela, cuentos pero también teatro-, fundamentalmente aquellos en prosa que se dedican a explorar lo que de alguna forma podría suceder y que denominamos ficticios. Por otro lado no debemos escatimar las diversas formas de literatura de carácter testimonial - memoria, biografías, crónicas de viaje, dietarios, cuadros de costumbre-, cuya materia central es referir lo que ya ha sucedido y a los que conviene dejar de denominar como tradicionalmente se ha venido haciendo con el epíteto de no ficticios y asumir otro tipo de terminología para referirnos a estos textos.

Si hablábamos antes de vasos comunicantes entre literatura y periodismo conviene dejar clara una cosa desde el principio. En primer lugar este flujo comunicativo entre ambos ámbitos de la expresión humana no se ha dado ni mucho menos se da en la actualidad en una sola dirección: el periodismo no solo no ha recibido múltiple influencia de la prosa ficticia, sino que es esta la que también ha sabido aprovechar para su desarrollo de abundantes materiales provenientes del ámbito de la comunicación periodística. En segundo lugar, hay que reconocer el hecho esencial de que buena parte de las convenciones con las que tanto literatos como periodistas arman sus textos no son, en rigor, propias de sus respectivos ámbitos de acción, como a menudo tiende a darse por supuesto, sino que más bien es propia de ese continente mayor que los comprende a ambos y que llamamos narrativa. Desde los orígenes con Homero y Hesíodo hasta los relatos de Kundera o Capote en una línea diacrónica; y desde la dificultad de la escritura automática hasta el supuesto grado cero expresivo de la redacción de noticias informativas pasando por la interacción del cómic contemporáneo, siguiendo una relación sincrónica, la habilidad retórica de los contadores de historias dando respuesta a la imperecedera necesidad humana de narrar la experiencia para hacerla inteligible ha desarrollado un amplísimo abanico de recursos comunicativos presentes en la intención y relación entre relatores y audiencias de toda condición. Y esto ha sido así desde la propia invención de la escritura como tecnología para dar rienda suelta, no solo a la memoria sino a la imaginación de los hombres. En palabras de Chillón

hoy parece mucho más atinado observar que, con harta frecuencia, tales procedimientos y procederes no pertenecen a la literatura de ficción ni a ninguna otra especie discursiva en concreto, sino más bien al feraz patrimonio de los relatos del mundo. ${ }^{2}$

Dejando a un lado el amplio debate sobre el periodismo como género literario que, poco a poco, se ha ido decantando hacia ver en el oficio de contar "la realidad" un hijo bastardo

\footnotetext{
1 Chillón, Ll. A. Literatura y periodismo: una tradición de relaciones promiscuas. Bellaterra (Barcelona), Universitat Autònoma de Barcelona, Servei de Publicacions, 1999, p. 77.

2 Ibid. "La escritura facticia”, en Blanco Alfonso I. y Fernández Martínez P. (coord.). Entre la ficción y la realidad. Perspectivas sobre periodismo y literatura. Madrid, Fragua, 2011, p. 24.
} 
de ese cajón de sastre que es la literatura, lo cierto es que sí existe algo que podemos llamar periodismo literario. Sería aquel que une las técnicas de la profesión con la intención informativa desarrollando técnicas para contar una historia con muchos de los elementos narrativos que conocemos. Sin duda, los dos géneros periodísticos que apuran esta unión son la crónica y el reportaje ya que aúnan algunas de las técnicas propias de la ficción para cautivar la atención del lector. ${ }^{3}$ Ahora bien, aunque el periodismo pueda ser calificado de literario jamás renuncia a su naturaleza informativa sino que más bien al contrario "la perpetúa en escrito que trascienden al papel barato". ${ }^{4}$

En primer lugar no hay que olvidar que es el lenguaje, ya sea literario o icónico o una mezcla de ambos como es el caso del cómic, la primera herramienta con la que cuenta el escritor y por tanto no importan cuáles sean más allá sus fines. Reconstruir la realidad significa delimitar un hecho tanto temporal como espacialmente y recrear los detalles dentro de ese microcosmos determinado. En la crónica periodística se produce una especie de viaje contrario. Partiendo de lo particular se trata de ofrecer un fresco general, de ahí su enfoque en lo que aparentemente nos resulta corriente, en un intento de enriquecer los hechos que de alguna manera escapan a las versiones oficiales. Los grandes cronistas admiten su receta en cada una de sus obras, así por ejemplo Ryszard Kapuscinski: "siempre he evitado las rutas oficiales, los palacios, las figuras importantes, la gran policía". ${ }^{5} \mathrm{Las}$ palabras del maestro de reporteros polaco serán seguidas al pie de la letra por Joe Sacco uno de cuyos cómics reportaje será objeto de nuestro estudio.

Pese a todo, hay una diferencia obvia entre periodismo y literatura y es que el periodista debe ser, de alguna forma, fiel a los hechos y además mantener en sus textos señales claras que permitan comprobar dicha fidelidad. Parafraseando a Sándor Marai, lo único seguro son los hechos, la realidad... Todas nuestras explicaciones de los acontecimientos están viciadas por un halo literario. La ficción mantiene con el lector un cierto compromiso de verosimilitud, sin embargo, en periodismo este compromiso se establece con la veracidad. Como ocurre con la autobiografía, estamos ante un nuevo pacto:

[E]1 ficcionador (sic) levanta una historia que aparenta ser verídica, mientras que el periodista rehuye de todo aquello que no consta como sucedido. Mientras que el primero construye a partir de artificios, el segundo realiza un camino inverso y desbroza la historia para desmontar todo aquello que parezca falso. El ficcionador, aun cuando se haya inspirado en la realidad, disuelve las referencias. Fusiona y diluye ambientes y personajes. Inventa, imagina. Pero el periodista no especula con los pensamientos o sentimientos de sus personajes; no fabrica elementos (sucesos, lugares, climas, objeto, declaraciones); respeta la cronología de lo sucedido; advierte cuando se ha acordado el anonimato de la fuente y lo que implica mantener esa promesa. E1 lector intuye ese pacto, tan distinto en cada caso, y lo refrenda, o no, en las primeras líneas. ${ }^{6}$

Será especialmente a mediados del siglo xx, cuando las representaciones de lo real y lo imaginario, la ficción y lo no ficticio, comiencen a abrazarse en distintas formas discur-

\footnotetext{
${ }^{3}$ No profundizaremos en este trabajo en la teoría sobre los géneros periodísticos. El lector interesado puede acudir a los múltiples volúmenes teóricos que hay sobre la materia como por ejemplo 21 Lecciones de reporterismo (1998). Este ha sido el manual que ha servido para nuestro análisis.

${ }^{4}$ Chiappe, D. Tan real como la ficción: (herramientas narrativas en periodismo). Barcelona, Laertes, 2010, p. 9.

5 Kapuscinski, R. Ébano. Barcelona, Anagrama, 2000, p. 5.

${ }^{6}$ Chiappe D. Op. cit.pp. 10-11.
} 
sivas que en el ámbito periodístico se conocerán como Nuevo Periodismo. Más allá de ejercer de filtradores de hechos, los trabajos encajados en el Nuevo Periodismo, forzaron a los lectores a considerar que la idea de verdad nunca es completamente objetiva y que los hechos, por sí solos, no necesariamente revelan un evento determinado de la forma más adecuada. ${ }^{7}$

Este Nuevo Periodismo surge como una respuesta y, a la vez reacción, a los medios de comunicación de la época y mantiene vínculos con la naciente cultura underground de la que el cómic contemporáneo es a la vez fuente y resultado. Hoy, trabajos herederos del Nuevo Periodismo en sus muy distintas denominaciones pueblan las estanterías de cualquier librería y, frecuentemente, los primeros puestos en las listas de ventas. Por supuesto, ahora ya no nos referimos a estos títulos bajo la etiqueta genérica de Nuevo Periodismo, sino que muchos se engloban en la categoría de literatura de no ficción, un calificativo problemático que ha dado lugar a múltiples conceptos derivados como narrativas postficcionales o, en el ámbito anglosajón, faction literature, un neologismo surgido a partir de la contracción de las formas inglesas fact y fiction. ${ }^{8}$

En el ámbito hispano tenemos el adjetivo facticio. Según el Gran Diccionario de la Lengua Española (1996) este término se refiere en su primera acepción a algo "que está hecho de manera artificial a imitación de la realidad natural”. Esta definición se queda, a mi juicio corta y es problemática, por lo que, al igual que otros investigadores como Albert Chillón, este adjetivo debería tener

\begin{abstract}
una acuñación complementaria, como designación de los enunciados de vocación veridicente, y sustituir así con ventaja la falaz y periclitada expresión «no ficción». En lo facticio existe, ya pues, una con-figuración, se da esa inevitable cuota de ficción tácita inherente a todo acto de dicción. Un enunciado "ficticio», en cambio, es aquel en que no existe vocación veridicente, sino fabulación explícita y deliberada - a veces en busca de una verdad esencial que transcienda la mera veracidad de los datos comprobables.
\end{abstract}

De unos años a esta parte, otro medio ha ido emergiendo como espacio para discursos más allá de la ficción: el cómic. Basta con acudir a cualquier librería especializada para darse cuenta de que la lectura de cómics ha transcendido - para bien — de sus ámbitos tradicionales hasta extenderse a públicos que ya no constituyen el objetivo original de las editoriales. De esta forma, memoria, narrativas documentales, hechos, texto e imagen, pero hechos al fin y al cabo, se funden para dar lugar a un subgénero nuevo dentro del cómic de no ficción o faction cómic, el cómic periodismo o periodístico.

En el presente trabajo usaré este término para referirme a aquellas obras cuya base es el relato de unos hechos reales documentados por distintas fuentes a cargo de un dibujante

\footnotetext{
7 Numerosos son los volúmenes que se pueden consultar acerca del género. Para comenzar el libro El nuevo periodismo (1977), de Tom Wolfe, es una especie de antología fundacional de este. Ronald Weber escribió en The Reporter as Artist (New York, Hastings House, 1974) una serie de ejemplos tomados de autores como Twain o Hemingway que según él demostraban que el Nuevo Periodismo ni era nuevo ni era periodismo sino solo literatura hecha por periodistas. Más allá de las discrepancias propias de cualquier género discursivo, es fácil ver elementos del llamado Nuevo Periodismo en obras como Operación Masacre, del argentino Rodolfo Walsh, publicada en 1957, por lo tanto muy anterior a las de los autores clásicos que se relacionan con el género, como el mencionado Wolfe, Capote o Mailer.

8 González de la Aleja (1990) recoge otras etiquetas como parajournalism, journalit, factual fiction, faction, periodismo de vanguardia, ficción ensayística o no-ficción creativa.
}

${ }^{9}$ Chillón, A (1999). Op. cit.p. 79. 
con un interés que va más allá del puramente artístico. Hay otras etiquetas para referirse a obras de autores como Joe Sacco, Emmanuel Guibert y Didier Lefèvre, Guy Delisle o en cierto sentido la propia Marjane Satrapi, por citar algunos de los nombres más importantes: periodismo gráfico o cómic reportaje. Las páginas del suplemento literario del diario El País recogían hace unos años un reportaje en el que se hacía eco del también llamado periodismo gráfico, bajo el título más o menos exacto de "Noticias dibujadas". ${ }^{10}$

De la misma forma que el escritor es alguien que observa la realidad para (re)construirla, en la viñeta, por su decodificación sencilla en texto y / o imagen, el autor de cómics se permite enviar mensajes inequívocos al lector. El dibujo secuencial, la esencia del cómic como medio de comunicación diferenciado, requiere una planificación narrativa más propia de otros medios como son la televisión o el cine. El cómic congela el tiempo en imágenes detenidas, pero, al convertirlas en secuencia, les proporciona movimiento y posibilidad de cambio, y lo hace, como ocurre con cualquier relato, con una intención determinada. Por eso el cómic aporta un significado mucho más amplio y duradero que el fotoperiodismo, cuya imagen está congelada en el tiempo y en el espacio, puesto que los medios de comunicación no acostumbran a editar series de imágenes de una misma historia.

Joe Sacco es, sin lugar a dudas, el mayor exponente del cómic periodístico mundial no solo por su condición de dibujante y guionista de cómics sino porque es periodista de profesión. Nacido en Malta en 1960, aunque de nacionalidad estadounidense, se licenció en Periodismo en 1981 en la Universidad de Oregón. Tras publicar sus primeros cómics en el circuito alternativo de Portland, en 1988 comienza su actividad viajera.

Desde 1993 hasta 1995 publica, de forma serializada, su primera gran obra, Palestina: en la franja de Gaza (2007) ${ }^{11}$, donde plasma sus propias experiencias en los territorios palestinos, en los que se sumergió durante dos meses. Será tras la aparición de este trabajo cuando alcance cierto prestigio en el mundo del cómic y sea galardonado con el prestigioso premio American Book Awards en 1996, un reconocimiento tradicionalmente asociado a la literatura. Encontramos aquí el primer punto de unión de la obra de Sacco con Art Spiegelman y su Maus, premiado con el Pulitzer en 1992, eso sí, dentro de una categoría llamada "Premio especial de las letras".

En el año 2000, Sacco publica su siguiente obra larga, Gorazde: zona protegida (2006), acerca de la guerra civil en Bosnia oriental y por la que se le otorga el galardón Guggenheim Fellowship. Posteriormente, en 2003, y a modo de continuación del anterior trabajo, publica El mediador (2004), de nuevo centrado en el conflicto de la antigua Yugoslavia, una temática que repetiría en El final de la guerra (2006) y que recopila sus experiencias y sus viajes por la convulsa zona de los Balcanes. Finalmente, en diciembre de 2009, se publicó en EE. UU. Notas al pie de Gaza (2010). En ella regresa a los territorios ocupados para realizar un verdadero ejercicio de periodismo de investigación en el que reconstruye una matanza de civiles palestinos ocurrida en 1956 de la que poco o nada se había recogido en los medios de comunicación tradicionales. Se trata, como Defoe hiciera 287 años

${ }^{10}$ Magi, L. "Noticias dibujadas", en Babelia, suplemento literario de El País del 24 de abril de 2010, pp. 5-8, disponible on line en http://www.elpais.com/articulo/portada/Noticias/dibujadas/elpepuculbab/2010 0424elpbabpor_1/Tes. [Consultado el 06-11-2012]

11 Esta fecha y las siguientes entre paréntesis indican el año de publicación en castellano de las obras. 
antes, de una nueva y minuciosa investigación de un suceso real esta vez en un cómic. E1 propio Sacco tiene muy clara la naturaleza de su trabajo:

\begin{abstract}
Hago tebeos periodísticos porque es la manera más fácil de unir mis dos pasiones, los cómics y el periodismo. No tengo ninguna teoría que me permita explicarlo. Sencillamente siempre me gustó la actualidad y, a veces, suceden cosas en el mundo que me llevan a hacer algo al respecto. Y lo más útil que se me ocurre en el momento es ir allí e informar de que es exactamente lo que está sucediendo. ${ }^{12}$
\end{abstract}

Sacco no se mueve en el terreno con la urgencia que suele acompañar a los reporteros que a diario cubren los conflictos internacionales, no depende de horarios de cierre y demás, sino que se mete de lleno en los acontecimientos para conocerlos de primera mano o por medio de sus protagonistas, al lado de los cuales se sitúa siempre.

Sus novelas gráficas tienen un vínculo estrecho con el Nuevo Periodismo y se inscriben en toda la tradición literaria no ficticia o faction literatura. En este sentido, Versaci va incluso más allá:

\begin{abstract}
Los cómics periodísticos resaltan estratos de significados inaccesibles para la prosa periodística al uso, pues estos proporcionan un lenguaje gráfico que combina palabra e imagen. Lo que es más, como los nuevos periodistas, los cómics periodísticos adoptan una postura anti «oficial» y una actitud «anticorporativa». No obstante, de la misma forma que se ha producido una absorción del Nuevo Periodismo por parte del mainstream y, como resultante, la disolución de su mensaje radical, los cómics periodísticos retienen, paradójicamente, un poderoso estatus marginal que dificultará, a estas obras, ser plenamente asimiladas. Cuando se habla de literatura periodística, los cómics periodísticos suelen estar incluidos, por la forma en que tienen de presentar sus historias, de una manera completamente inviable para la prosa periodística, —nueva-, o de otra naturaleza. ${ }^{13}$
\end{abstract}

El cómic periodístico, como el Nuevo Periodismo, continúa en la senda de poner en duda el discurso establecido. Notas al pie de Gaza comienza precisamente con una reflexión acerca de los discursos oficiales y su relación con la historia hasta el punto de que veremos la obra como un discurso contra la oficialidad en su totalidad.

En una evocadora secuencia de tres páginas (pp. 4-6) sobre el papel del periodismo a la hora de abordar conflictos enquistados en el tiempo, de vuelta en la ciudad palestina de Khan Younis, el autor se encuentra con amigos y colegas periodistas (pp. 3-4), va a un bar frecuentado por la profesión y en apenas página y media llena de cinismo explica las sensaciones de aquellos que narran el conflicto día a día. Habla su voz: "Están todos sacudiéndose el polvo de la jornada de trabajo, se toman el primer trago de la noche y charlan con el palique enrevesado de veteranos y gacetilleros". A continuación, una viñeta estrecha y horizontal. Las bocas de los presentes y el diálogo en el aire: “¿Dónde has estado hoy? ¿Hebrón? ¿La emboscada? ¿Cuántos muertos? ¿Cómo afectará esto a... (sic)?” ${ }^{44} Y$ de ahí a la siguiente página. Alguien llama a la camarera para pedirle un menú. Y este se desplie-

\footnotetext{
${ }^{12}$ Magi, L. "No soy objetivo pero sí honesto". Entrevista a Joe Sacco en El País del 25 de octubre de 2009. Disponible on line en http://www.elpais.com/articulo/cultura/soy/objetivo/honesto/ elpepucul/20091025elpepicul 1/Tes. [Consultado el 06-11-2012]

${ }^{13}$ Versaci, R. This Book Contains Graphic Language: Comics as Literature. London / New York, Continuum, 2007, p. 111.

${ }^{14}$ SAcco, J. Notas al pie de Gaza. Barcelona, Random House Mondarori, 2010, p. 4.
} 


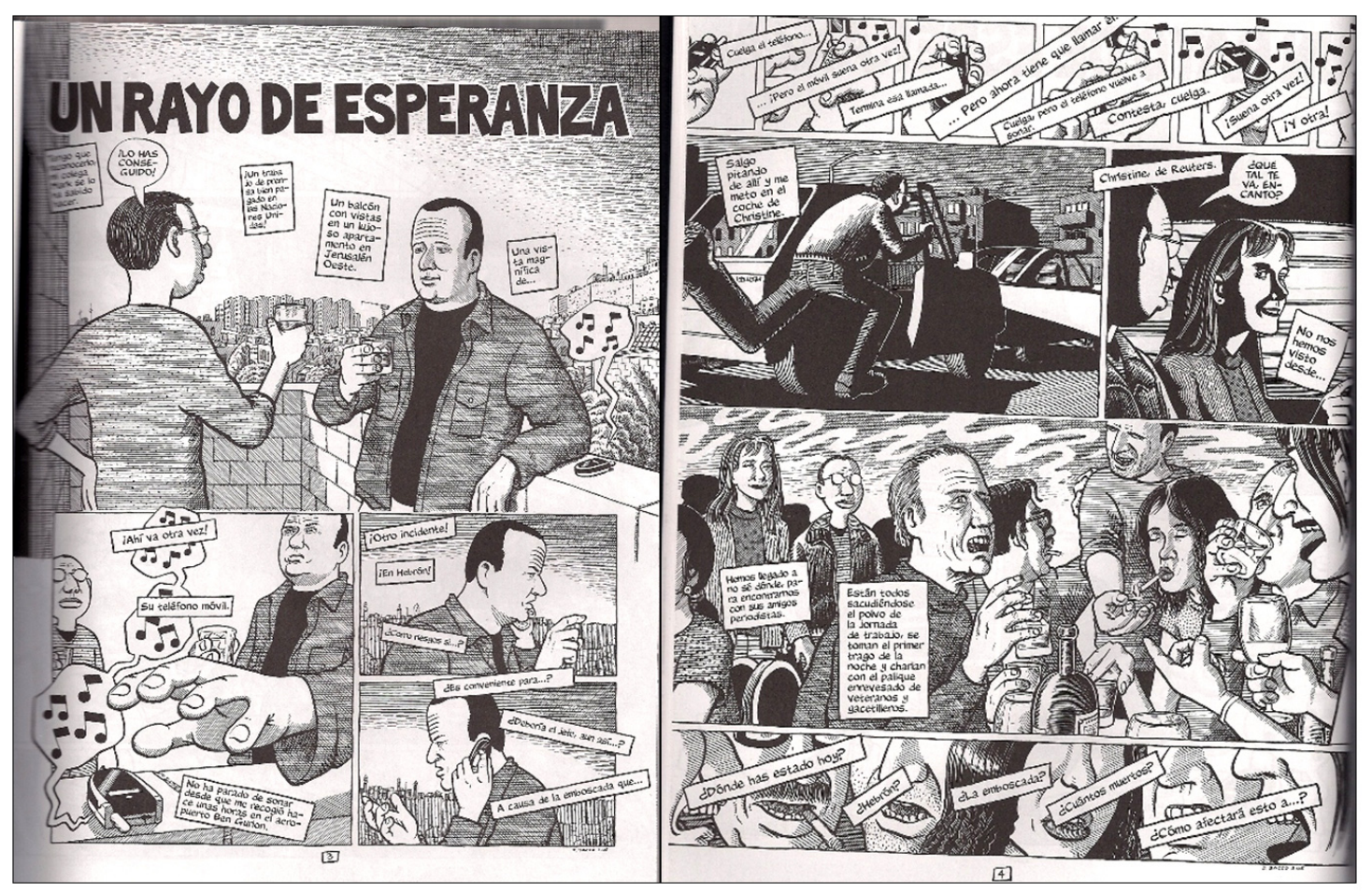

FIG. 1. Notas al pie de Gaza. Joe Sacco (2010). pp. 4-5.

ga en una nueva viñeta horizontal cargada de significado: El menú normal de cualquier restaurante se desdobla en hojas, en ellas un autobús en llamas, un coche ardiendo y un tanque disparando. Sobre las ilustraciones el texto, de nuevo la voz crítica del autor:

¡Bombardeos! ¡Asesinatos! ¡Incursiones! Podrían presentar hoy la noticia de hace un mes -o del año pasado en realidad-, y ¿quién notaría la diferencia? Han exprimido cada palabra posible de la segunda intifada, han fotografiado a cada madre que gemía, han citado las mentiras de cada portavoz, han detallado cada humillación... ¿`Y qué? ${ }^{15}$

En ese “¿Y qué?” final está encerrado todo el sentido de sus obras. No importa lo que ocurra, nada cambiará en la espiral de silencio — o ruido-, en la que los grandes medios han convertido los conflictos sin resolver. Se trata de una clara crítica a la sociedad pero también a la labor de los informadores, por lo que más adelante comunica al lector el sentido de su obra:

Esta es la historia de unas notas a pie de página de un incidente secundario de una guerra olvidada. De una guerra que, en 1956, enfrentó a Egipto y la extraña alianza de Gran Bretaña, Francia e Israel. El incidente secundario son los ataques y contraataques a lo largo de la frontera de Gaza, entre guerrillas palestinas y fuerzas israelíes. Y las notas a pie de página... Bueno, tal como suele pasar, esas notas al margen quedaron relegadas, en equilibrio precario, al final de las páginas de la Historia. La Historia puede prescindir de las notas a pie de página. Las notas a pie de página son, en el mejor de los casos, innecesarias; y en el peor desvirtúan la parte importante del relato. De vez en cuando al aparecer nuevas ediciones, más genéricas y racionalizadas, la Historia suprime completamente muchas de esas notas. La Historia tiene llenas las manos. No puede evitar generar páginas cada hora, cada minuto. La Historia se atraganta con sucesos recientes y engulle tantos de los antiguos como puede. ¿La guerra de 1956? ¿Qué? ${ }^{16}$

\footnotetext{
15 Ibid.p. 5.

16 SAcco, J. Op. cit. 2010, pp. 8-9.
} 
A lo largo de dos páginas, Sacco mezcla tiempos y episodios para conformar un discurso suficientemente revelador. Constantemente repite la expresión "notas al pie" para referirse a los pequeños sucesos que escapan al conocimiento dado por la Historia oficial. Contra esa oficialidad dispone ahora su trabajo, una reconstrucción de un episodio olvidado de la guerra de 1956 en el que más de un centenar de palestinos fueron asesinados por el ejército israelí en la ciudad palestina de Kahn Younis.

Frente al cómic clásico de aventuras, una de las características que más se repetirá en los cómics no ficticios es la autorreferencialidad, un aspecto capital en las obras del Nuevo Periodismo. El yo autor aparece dentro de la acción o, cuando menos, ya no se esconde tras la objetividad de la noticia estricta. La verdad de los hechos cotejables será reemplazada ahora por la verdad que aporta el propio periodista, de manera que el autor hace explícita su actitud creativa:

Como siempre, me dibujo en mis planchas. Los lectores entienden así que lo que ven es mi punto de vista personal. Estudié periodismo, pero creo que la objetividad es una ilusión. Cuando preparamos un reportaje seleccionamos el material. No soy objetivo, pero sí trato de ser honesto. Por eso entro en la escena, es mi manera de aclarar que soy filtro y lupa de la historia. ${ }^{17}$

En Notas, Sacco se sumerge en el discurso que permanece fuera de las grandes cadenas de noticias y los libros de historia, y el cómic es una sucesión de escenas en las que el Sacco periodista recaba multitud de testimonios deseosos de contar lo sucedido. Los testigos le ofrecen versiones del mismo hecho, lo cual no deja de ser una vez más un guiño al trabajo periodístico: el discernir entre ellas la más adecuada, la más cercana a la veracidad de lo acontecido. Sacco, acompañado de su guía, se resiste a dar por buena una versión definitiva de los hechos y busca nuevos detalles y diferentes puntos de vista entre los testigos, que, cómo no, incluyen a representantes del bando israelí.

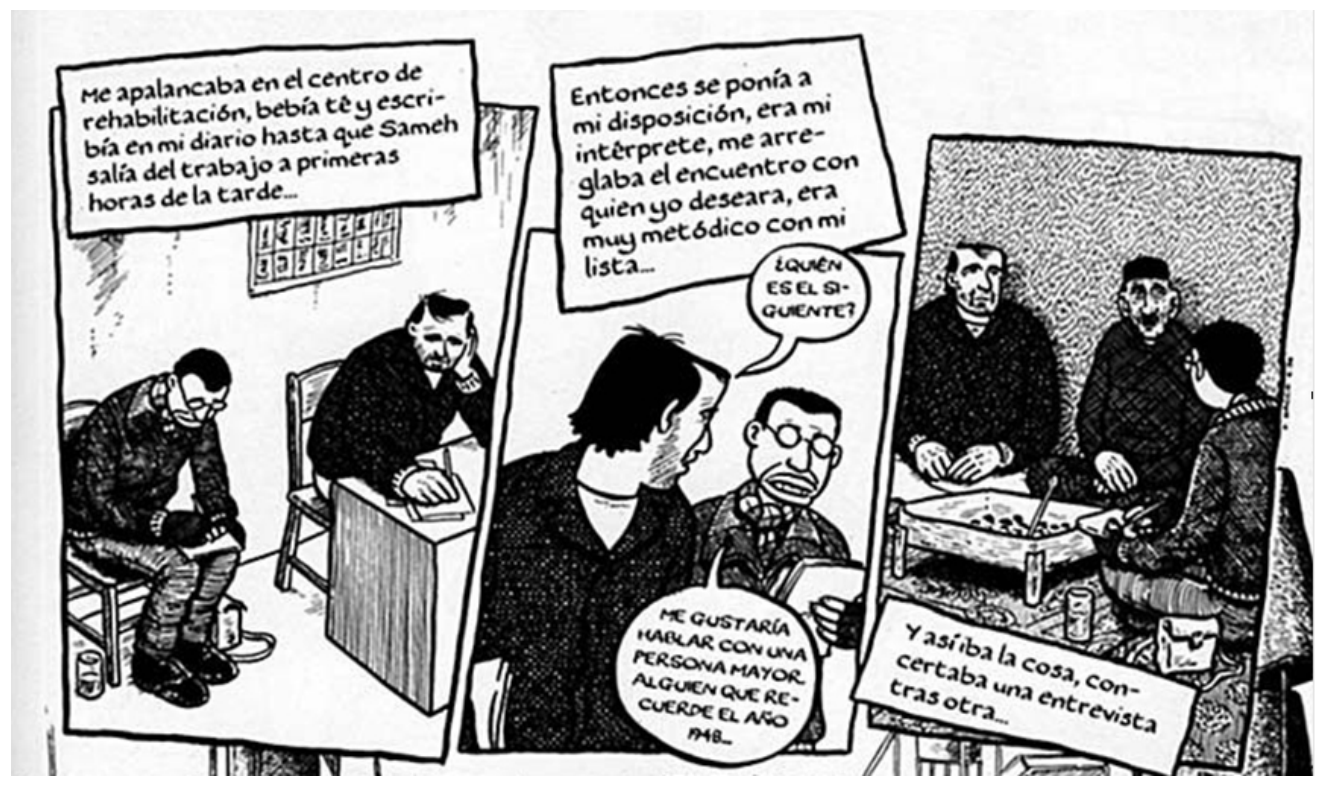

FIG. 2. Notas al pie de Gaza. Joe Sacco (2010). pp. 183.

17 Magi, L. Op. cit. 2009. 


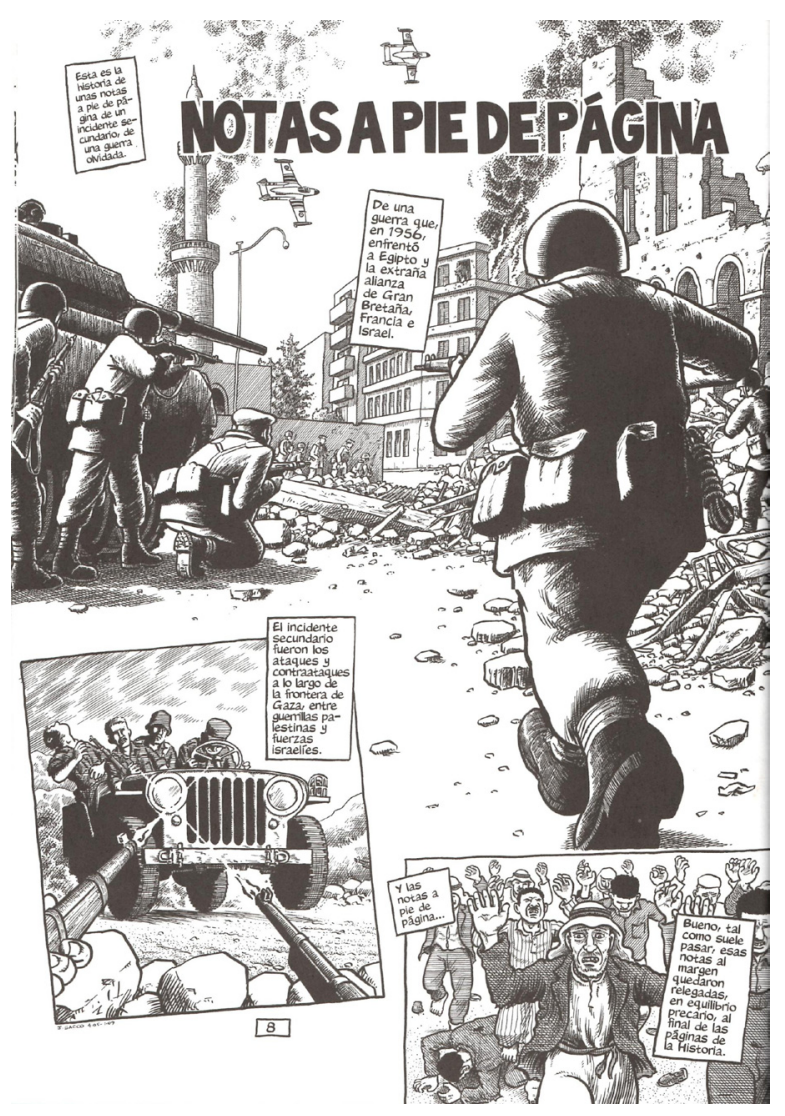

FIG. 3. Notas al pie de Gaza. Joe Sacco (2010). p. 8.

El trabajo de Sacco en sus obras consiste en recrear el material auténtico que le proporcionan sus fuentes o su propia experiencia en dos niveles narrativos temporales. Por un lado, el "presente" en el que el autor escucha y recoge el testimonio de su fuente; y por otro, recrear este testimonio pasado en viñetas que narren el acontecimiento referido. Si bien es cierto que lo suyo no es producir nada original, como un escritor del Nuevo Periodismo, sí deja una parte a la creatividad:

Hago decenas de entrevistas, como cualquier periodista. Sin embargo, lo que necesito son sugestiones visuales, así que a veces planteo a mis fuentes preguntas muy raras, del tipo: «¿Cómo ibas vestido?». No paro de tomar fotos de los mismos detalles: un coche, una casa; a la hora de representarlo no quiero inventar nada. Dibujo solo cuando no es recomendable sacar la cámara, en los check point, por ejemplo. Los soldados israelíes no agradecen las fotos, entonces esbozo con el bolígrafo. Cada vez que cruzo voy añadiendo detalles. ${ }^{18}$

Todo acto de escritura exige un proceso mental previo. Por lo tanto, el periodista, necesita interpretar los hechos y proceder a una discriminación, lo que, por otro lado, supone una herida contra la objetividad periodística falsamente entendida. Así lo explica el propio Joe Sacco con respecto a Notas al pie de Gaza: "Primero paso las grabaciones y ordeno todo mi material. Tardé tres meses para Notas. Luego, por fin, arranco. Sin esperar. No quiero que se me vaya de la boca el sabor de las historias". ${ }^{19}$ Pero siempre, teniendo en

\footnotetext{
18 Magi, L. Op. cit. 2009.

19 Ibid.
} 


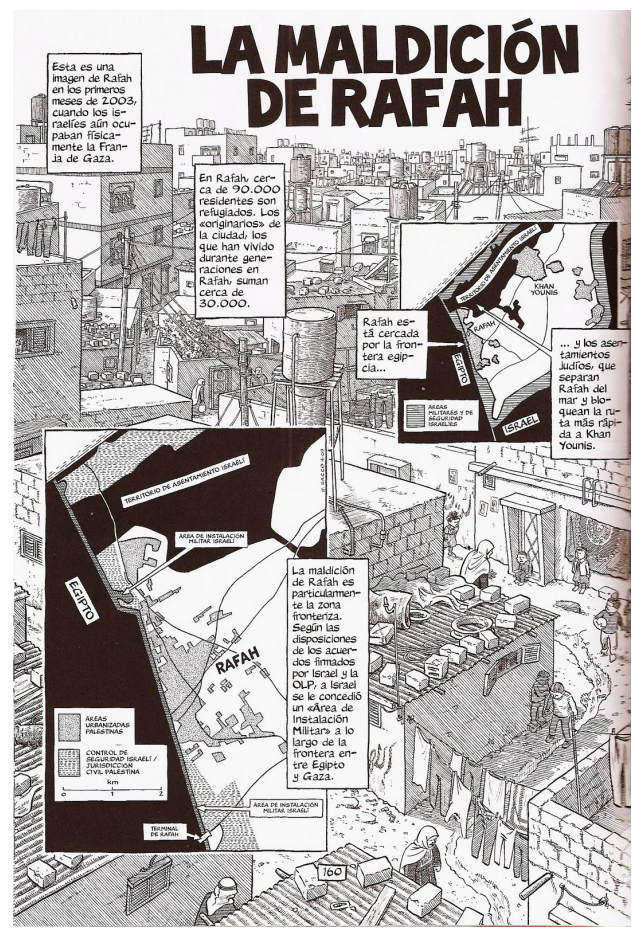

FIG. 4. Notas al pie de Gaza. Joe Sacco (2010). p. 160.

cuenta lo que J. Hersey denomina la sagrada regla del periodismo: "El escritor no debe inventar. La leyenda debe ser: NADA DE ESTO HA SIDO INVENTADO (sic)” ${ }^{20}$

Sacco, como reportero que es, ejerce de guía entre dos mundos. Esto deja fuera los maniqueísmos propios de los cómics de superhéroes, algo que encontramos explícitamente tratado en el personaje de Khaled (Notas), cuyo testimonio, el propio autor pone en duda en ocasiones y no sabe cómo tratarlo en su historia.

En El nuevo periodismo (1973), Wolfe perfila un cuarteto de recursos técnicos que conforman el texto neoperiodístico y que asocia con escritores realistas decimonónicos. La escena, el diálogo, la descripción significativa, y la perspectiva aportan a la noticia, según Wolfe, esa nueva dimensión de la que carecía con anterioridad. ${ }^{21}$ Todos y cada uno de estos recursos están presentes en los libros de Sacco. La obra ya no es una mera narración lineal, sino escenificaciones actuadas de la información recogida por el periodista en las que la caracterización, las conversaciones y la ambientación añaden una magnitud humana frecuentemente olvidada por el periodismo tradicional. De esta forma, las tradicionales cinco $W$ del periodismo — dónde, cuándo, cómo, quién y por qué- aparecen manipuladas de tal forma que el centro de la historia recae en las narraciones e intervenciones de los seres humanos convertidos en personajes. ${ }^{22}$

\footnotetext{
${ }^{20}$ Citado en González de la Aleja Barberán, M. El Nuevo Periodismo norteamericano. Albacete, Ediciones de la Diputación de Albacete, 1990, p. 124.

${ }^{21}$ Wolfe, T. El nuevo periodismo. Barcelona, Anagrama, 1973, p. 24.

${ }^{22}$ En el periodismo, el concepto de las cinco $W$ (también conocido como las cinco $\mathrm{W}$ y una $\mathrm{H}$ y como las seis W) está vinculado a la redacción y presentación de noticias, así como a la investigación científica, y a la investigación policial, que se considera básico en la reunión y presentación de información. Se trataría de una fórmula básica con la que llegar a construir la historia "completa" sobre un acontecimiento determinado. La máxima de las cinco $W$ es que para que la historia esté completa, debe responder a una lista de verificación de seis preguntas, cada una de las cuales comprende una palabra interrogativa en inglés: Who?
} 
El propio Tom Wolfe señala una conclusión semejante a la hora de hacer balance sobre algunos de sus escritos:

Lo que me interesó no fue solo el descubrimiento de que era posible escribir artículos muy fieles a la realidad empleando técnicas habitualmente propias de la novela y el cuento. Era eso... y más. Era el descubrimiento de que en un artículo, en periodismo, se podía recurrir a cualquier artificio literario, desde los tradicionales dialogismos del ensayo hasta el monólogo interior y emplear muchos géneros diferentes, o dentro de un espacio relativamente breve... para provocar al lector de forma a la vez intelectual y emotiva. ${ }^{23}$

Pese a que habla también de "un espacio relativamente breve", Wolfe está pensando en el género del reportaje cuando hace sus afirmaciones. Lorenzo Gomis define el reportaje por oposición a la información que es la noticia escueta que comunica con exactitud y eficacia un hecho nuevo. Frente a ella, el reportaje satisface las necesidades informativas a las que no llega la noticia:

Acerca al lector al lugar del suceso, le permite comprender la articulación de una serie de hechos. El reportero se acerca al lugar de los hechos, a sus actores, testigos y con los recursos de la literatura y la libertad de un texto firmado, hace que el lector se haga cargo de lo que fue el hecho en su ambiente..$^{24}$

El reportaje es el género periodístico que más libertad otorga al redactor y que hoy en día goza de mayor prestigio. Sin embargo, no siempre fue así. El propio Wolfe recuerda que a mediados del siglo pasado en la prensa norteamericana, el reportaje era el término periodístico "que denominaba un artículo que cayese fuera de la categoría de noticia propiamente dicha". ${ }^{25}$ Lo incluía todo y sus autores eran poco menos que seres un tanto marginales en las redacciones. El autor de La hoguera de las vanidades escenifica esta situación de una manera muy gráfica aludiendo a que "los redactores guardan sus lágrimas para los reporteros de guerra. En cuanto a los que escriben reportajes... cuanto menos se hable, mejor" ${ }^{26}$ En su opinión, el destino manifiesto de los autores de reportajes era, cómo no, escribir la "gran novela americana", ya que, ayer más que hoy, el novelista era el héroe, "no había sitio para el periodista, a menos que asumiese el papel del aspirante a escritor o de simple cortesano de los grandes" ${ }^{27}$ Pero todo eso cambió a mediados de los años sesenta con el descubrimiento de un periodismo que, no solo se podía escribir con elementos propios de la novela, sino también leer como una novela.

Vistos en perspectiva, los libros de Sacco no son otra cosa que grandes reportajes o sumas de reportajes más pequeños, en los que toda acción es siempre una recreación (mediante viñetas) que viene dada por el relato de los testimonios y las fuentes. El maltés desarrolla todas las estrategias propias de la narrativa secuencial al mismo tiempo que comparte

\footnotetext{
(¿Quién?) What? (¿Qué?) Where? (¿Dónde?) When? (¿Cuándo?) Why? (¿Por qué?) y How? (¿Cómo?).

${ }^{23}$ Wolfe, T. Op. cit. 1973, p. 26.

${ }^{24}$ Citado en Bezunartea, O., Martínez, L., Del Hoyo, M. 21 lecciones de reporterismo. Bilbao, Universidad del País Vasco, 1998, p. 109.

${ }^{25}$ Wolfe, T. Op. cit. 1973, p. 23.

${ }^{26}$ Ibid. p. 17.

${ }^{27}$ Ibid.
} 
una serie de rasgos con los escritores de no-ficción creativa. La primera de estas características es la de convertir a las personas en personajes y así va deslizando cada uno de los testigos con los que se entrevista para recabar informaciones e historias, Abed, el guía que lo acompaña durante su investigación, el León, el guerrillero Khaled, o los israelíes que tratan de explicarle la otra cara del conflicto de Oriente Medio. Sacco siempre nos da destellos de la propia historia personal de todos ellos.

Si bien la mayor parte de las fuentes consultadas por Sacco son directas, testigos y víctimas, también aparecen otras institucionales: en Notas, por ejemplo, estas son de dos tipos. Las primeras documentales (archivos oficiales de la ONU, la UNRWAUnited Nations Relief and Works Agency-, las Fuerzas de Defensa Israelí, el Estado de Israel, el archivo de la Knést - parlamento israelí-, etc.), las segundas, soldados y oficiales que conocieron de primera mano los hechos y que aparecen detallados en las últimas partes del libro. Asimismo, en diversos momentos donde la narración se hace más documental e histórica, Sacco opta por dibujar directamente a personajes históricos implicados como Ben Gurion; Gamal Abdel Nasser, presidente de Egipto desde 1956 hasta su muerte en 1970; o Moshe Dayan, héroe para los israelíes, genocida para el pueblo palestino como jefe del Estado Mayor del ejército israelí, crucial en la Guerra de los Seis Días.

Como periodista, Sacco busca con su testimonio contextualizar los hechos históricos pero también contrastar los relatos que obtiene de las víctimas; en ocasiones, este ejercicio sirve para ponerlos en duda. El autor es siempre consciente de que el suyo es un relato no ficticio en el que su propia naturaleza, periodismo, se ve reflejado como profesión y como discurso dejando patentes sus propias limitaciones y trabas: la capacidad de percepción, la memoria y la destreza del reportero, etc., haciendo gala de una dimensión meta periodística. Del mismo modo, nos brinda otras señales que prueban que el texto no es nunca una ficción, como pueden ser la presencia de prólogos explicativos y epílogos que ratifican el origen y las circunstancias en que la historia ha sido confeccionada así como mapas y documentos de carácter orientativo. Frente al novelista que crea un universo a su medida, Sacco se encuentra con un mundo hecho con sus propias reglas de funcionamiento. Por eso, en ocasiones, se muestra desorientado y hace partícipes a los lectores de esta desorientación lo que viene a reforzar esa sensación de realidad que no puede ser dominada por un autor a su antojo.

A medida que Sacco avanza en su investigación, crecen sus dudas acerca del trabajo que está realizando. Así se lo hace notar al lector con la introducción de un capítulo titulado "La memoria y la verdad esencial". Las palabras de Sacco al comienzo de este son esclarecedoras:

\begin{abstract}
Acabáis de leer una serie de recuerdos personales que cuentan la historia de cómo, en Khan Younis, el tres de noviembre de 1956, soldados israelíes consumaron grandes matanzas de palestinos. Según los testigos, los hombres fueron muertos a tiros en casa o puestos en fila en la calle y fusilados contra el muro. Permitidme ahora que socave los pilares en los que se basa nuestra historia. No hace falta decir que los recuerdos cambian con los años, y los que aquí hemos removido son viejos de varias décadas. La memoria desdibuja los contornos, añade y sustrae. ${ }^{28}$
\end{abstract}

Sacco introduce aquí un capítulo reflexivo acerca de todo su trabajo y desliza uno de los conceptos más importantes para hablar, no solo de periodismo, sino de historia y, por ex-

\footnotetext{
${ }^{28}$ SAcco, J. Op. cit. p. 112.
} 
tensión, de determinadas literaturas de no ficción. Se trata de la memoria. No entraremos a discutir aquí la complejidad teórica que entrañan los estudios alrededor de este concepto y sus manifestaciones literarias, expoliadas fundamentalmente por la generación que sobrevivió al Holocausto y tan en boga ahora en España o la llamada Literatura de Testimonio de Latinoamérica. De nuevo, Sacco concatena testimonio y representación gráfica de los mismos en una secuencia de viñetas que no tiene fin. Estos testimonios son borrosos, se contradicen incluso y por eso advierte el autor en una viñeta en negro con un solo rótulo: “¿Qué sacamos de todo esto?”. Él mismo ofrece una respuesta:

\begin{abstract}
Me es imposible descifrar el sentimiento de culpa y el dolor que sufre quien sobrevive donde tantos otros han sucumbido [una reflexión que coincide con la de los supervivientes del Holocausto, de Primo Levi al propio padre de Art Spiegelman en Maus], ni sabría explicar qué puede inducir a una persona traumatizada a evocar la muerte de un hermano, no estando aquella allí suponiendo que así fuera. No pretendo con esto sino aludir a los problemas que conlleva basarse en testigos presenciales para contar nuestra historia. Pero nada de esto debería hacernos olvidar la verdad esencial: el 3 de noviembre de 1956, tres hermanos de Khamis fueron abatidos a tiros por soldados israelíes. Estaban, según sostiene un informe de la ONU, entre los 275 palestinos muertos aquel día en la ciudad y el campamento de Khan Younis. ${ }^{29}$
\end{abstract}

$\mathrm{Su}$ reflexión es muy clarificadora y daría para un largo debate sobre la memoria y los testimonios y cómo el investigador debe acercarse a ellos. Pero yo prefiero quedarme con el final y el posicionamiento de Sacco al aludir a un informe oficial de la ONU que reproducirá en el capítulo siguiente bajo el título "Documento". Sacco parece curarse en salud y apelar al buen sentido crítico del lector para que sea este quien saque sus propias conclusiones, pues él ya ha sacado las suyas.

Las obras de Sacco se comportan como literatura de testimonio en el sentido en que queda patente la participación de un interlocutor que transcribe o graba el relato de un testigo para luego trasladarlo a imágenes, de manera que aquel se convierte en narrador principal. La sucesión de episodios funciona en la mente del lector como las piezas del rompecabezas que deben ser colocadas por este para armar un todo. Este modo de trabajar puede resultar tedioso hasta para el propio Sacco. Así como ya había hecho en Palestina, confiesa su cansancio por hacer siempre lo mismo, llegar a una casa, participar en la ceremonia del té y disponerse a escuchar un nuevo drama personal donde se juntan torturas, parientes muertos y derribos de casas, y al final no obtener la información deseada. De esta manera, los cómics periodísticos de Sacco desembocan en narraciones corales en las que el periodista toma prestado el punto de vista de los personajes. El resultado es una fusión entre voces, la primera y la tercera, lo que da lugar a una nueva voz que acaba por no pertenecer ni al autor ni a sus testigos.

La sensación que transmite al lector siguiendo esta fórmula es doble: por un lado, el lector obtiene una visión de los hechos de primera mano, con una pátina de fidelidad a los mismos; por otro, la representación que Sacco realiza de sí mismo es, en muchas ocasiones, un tanto descalificadora, sobre todo en los momentos de mayor reflexión meta narrativa. El mencionado comienzo de Notas no puede ser más elocuente.

Por último, cabe señalar otra de las características más reveladoras en cuanto a la naturaleza periodística de las obras de Sacco, que viene dada por el juego de contrarios. Una de

${ }^{29}$ SAcco, J. Op. cit.p. 116. 


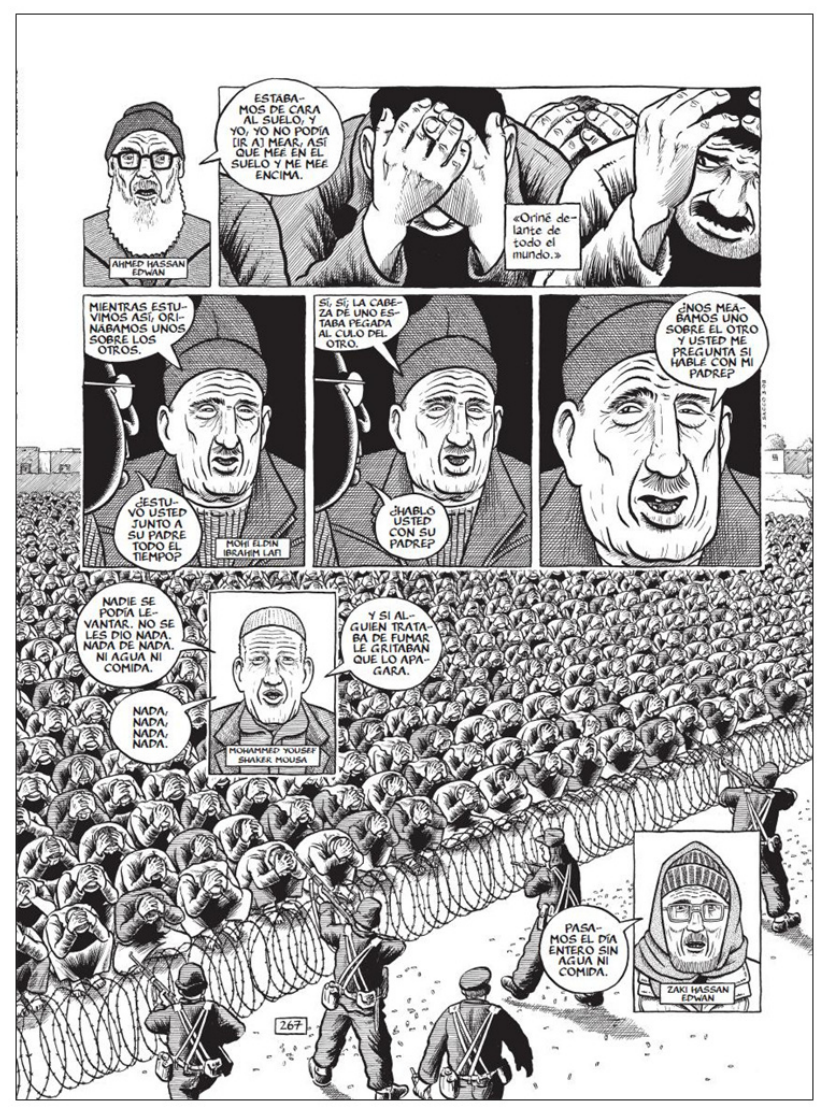

FIG. 5. Notas al Pie de Gaza. Joe Sacco (2010). p. 267.

las limitaciones del periodismo es la temporalidad con la que funciona: el pasado verbal confina el espectro temporal de interés, mientras que el relato debe de estar marcado por la inmediatez y la urgencia. Al igual que los autores del Nuevo Periodismo utilizaron con frecuencia el presente histórico para superar el aislamiento temporal, Sacco se instala en él para relatar su historia. De esta forma el lector se identifica con la experiencia expuesta porque comparte un mundo que, a fin de cuentas, es el suyo propio. Se integra mejor en el proceso narrativo porque el presente verbal es su mismo tiempo existencial; y hace que el texto se engalane con una cierta validez permanente de los detalles contados en presente. El cómputo general de lo anterior es que la no-ficción transmite algo que ya sucedió, pero que tiene ecos presentes. El propio Sacco lo resalta en su prólogo a Notas:

La génesis de este libro se remonta a la primavera de 2001, cuando la revista Harper's nos encargó al periodista Chris Hedges y a mí un trabajo en la Franja de Gaza [...]. Recordé la mención que muchos años antes había leído en el libro de Noam Chomsky, El triángulo fatal - básicamente una breve cita de un documento de las Naciones Unidas-, sobre una gran matanza de civiles en Khan Younis en 1956 [...]. Chris consideró que lo sucedido [...] era parte importante de la historia de la ciudad, e incluyó varios párrafos al respecto en el artículo [...]. Por alguna razón, los responsables de la revista eliminaron aquella sección. Aquello me molestó. Ese episodio [...] no merecía ser relegado al olvido de ese modo. ${ }^{30}$

Joe Sacco, periodista pero también creador de cómics, escribió esto hace nueve años y desde entonces poco o nada ha cambiado en los territorios ocupados. No obstante, su

\footnotetext{
${ }^{30}$ SACCo, J. Op. cit.p. IX.
} 
obra se erige como un documento de gran valor para realizar un acercamiento profundo a uno de esos episodios que permanecen arrinconados en los márgenes de la historia.

El autor maltés demuestra que un medio como el cómic - conviene no olvidar que eso es Notas por encima de todo-, tradicionalmente asociado a contenidos de naturaleza ligera, es perfectamente válido y adecuado para dar cabida a cualquier materia, por mucha seriedad que le presupongamos a esta. En su trabajo, Sacco combina el lenguaje clásico de la viñeta con un escrupuloso hacer periodístico - el periodismo que huye de falsos objetivismos para instalarse en la objetividad y la honestidad como únicos condicionantes- para realizar un auténtico reportaje largo sobre el conflicto árabe-israelí. Siguiendo el esquema clásico de los textos del llamado Nuevo Periodismo, el autor se coloca siempre en primera línea para desde su punto de vista ofrecernos un relato que viaja desde el detalle de las pequeñas historias a la totalidad de un tema de gran complejidad que es imposible de desentrañar sin la revisión de todas sus aristas.

Si bien no es el primero, Sacco se ha convertido con su última obra en el mayor y más convincente representante de lo que podríamos denominar sin temor a equivocarnos cómic periodístico, un subgénero a caballo entre distintas disciplinas que los grandes focos mediáticos parecen haber por fin descubierto. 


\section{Bibliografía}

Bezunartea, O., Martínez, L., Del Hoyo, M. 21 lecciones de reporterismo. Bilbao, Universidad del País Vasco, 1998.

Chiappe, D. Tan real como la ficción: (herramientas narrativas en periodismo). Barcelona, Laertes, 2010.

Chillón, A. Literatura y periodismo: una tradición de relaciones promiscuas. Bellaterra (Barcelona), Universitat Autònoma de Barcelona, Servei de Publicacions, 1999.

- "La escritura facticia”. Entre la ficción y la realidad. Perspectivas sobre periodismo y literatura. Ignacio Blanco Alfonso y Pilar Fernández Martínez (coord.). Madrid, Fragua, 2011, pp. 2033.

González De la Aleja Barberán, M. El Nuevo Periodismo norteamericano. Albacete, Ediciones de la Diputación de Albacete, 1990.

Kapuscinski, R. Ébano. Barcelona, Anagrama, 2000.

Magi, L. "No soy objetivo pero sí honesto". Entrevista a Joe Sacco en El País del 25 de octubre de 2009. Disponible on line en http://www.elpais.com/articulo/cultura/soy/objetivo/honesto/ elpepucul/20091025elpepicul_1/Tes. [Consultado el 06-11-2012]

- "Noticias dibujadas", en Babelia, suplemento literario de El Pais del 24 de abril de 2010, pp. 5-8. Disponible on line en http://www.elpais.com/articulo/portada/Noticias/dibujadas/elpepu culbab/20100424elpbabpor 1/Tes. [Consultado el 06-11-2012]

SAcco, J. El mediador: una historia de Sarajevo. Barcelona, Planeta De Agostini, 2004.

- El final de la guerra: reseñas biográficas de la guerra de Bosnia, 1995-96. Barcelona, Planeta De Agostini, 2006.

-Gorazde, zona protegida: La guerra de Bosnia oriental 1992-1995. Barcelona, Planeta De Agostini, 2006.

-Palestina: en la Franja de Gaza. Barcelona, Planeta De Agostini, 2007.

- Notas al pie de Gaza. Barcelona, Random House Mondarori, 2010.

Versaci, R. This Book Contains Graphic Language: Comics as Literature. London / New York, Continuum, 2007.

VV. AA. Gran Diccionario de la Lengua Española. Barcelona, Larousse Planeta, D.L, 1996. [Ed. en CD-ROM].

Wolfe, T. El nuevo periodismo. Barcelona, Anagrama, 1973. 